\title{
Conservation Strategies of a Rare Historical Carpet in Cairo University, A case study
}

\author{
Harby E Ahmed \\ Department of Archeology Conservation, Faculty of Archeology, Cairo University, Egypt
}

Received:December 14, 2018; Accepted: December 19, 2018; Published: December 21, 2018

*Corresponding author: Harby E Ahmed, Department of Archeology Conservation, Faculty of Archeology, Cairo University, Egypt, Email: harbyezzeldeen@cu.edu.eg

\begin{abstract}
Historical carpets that are still in use are subject to many risks and damage factors. Historical carpets object are located in the office of the President of the Cairo University, which dates back to the Ottoman periods during rule of Mohammed Ali family. The dimensions of the Carpet object are about 3.45 meters in width, 5.65 meters in length. It is decorated by a variety of plant motifs including flowers, and leaves. Historical carpets object contain various forms of damage such as dust, dirt which hard to remove, weakness, lost parts, and change in color grades. Firstly, close examinations were carried out to identify the type of fiber, type of dust, and other forms of damage. Scanning Electron Microscopy (SEM), FTIR, X-ray. In the beginning of conservation process, the weak parts were reinforced by stitching. Mechanical cleaning processes using different types of brushes and air suction were done. Dyes stability was tested for washing solutions, wet cleaning processes using water and neutral detergents were done. Complete the missing parts and strengthen by adding a new linen cloth to the back of carpet. All the conservation process was recorded by photograph.
\end{abstract}

Key words: Historical; Carpet; Dirt; Conservation; Fibers; Cleaning; SEM; FTIR

\section{Introduction}

Historical museums and houses contain a large number of historic carpets. Many researchers have pointed out that the original home of carpet makers is central Asia. This historic carpet is made of textile fibers, most notably wool fibers and silk fibers used in the manufacture of carpets. Different kind of natural dyes $s$ and natural fibers were used manufacturing of the historical carpets. Historical carpets are exposed to many deterioration factors that cause damage and decay in fibers and dyes. Deterioration factors such as oscillate relative humidity (RH), changing temperature, effect of light, effect of air pollution which results in weakness in fibers and dye, hardness in fibers, separate parts, loss parts, stain and dust [1] [2] [3-5].

\section{The Object}

Historical carpets date back to the late Ottoman era in Egypt During the period of the rule of his family Mohammed Ali. The Historic Carpets are located in the office of the President of the Cairo University. The carpet is still used where the office is located.

It is characterized by the presence of vegetative motifs of multiple shapes, such as flowers and flowers in various shades of color such as red, blue, brown, black, green.

Daily exposed to a huge amount of dust and smothering led to blur color grades and darkness in colors. They contain multiple damage features such as missing parts, adding to a general weakness in the edges. A change in the degree of acidity of the historical carpet resulted in chemical damage. Historic carpets are subject to restoration processes to get rid of dust, stains, impurities and acidity. Strengthens and complete the weak and lost parts of Historical Carpet were done. (Figure 1)

\section{Testing And Analysis}

Morphological study: Using Scanning Electron Microscope (SEM) is very important to identify the type of fibers, which used in the manufacture of historical carpets. Adding to the identification of the manifestations of damage in the fiber that nobody can see it by the naked eye. A small fiber from different parts of Historical Carpet was taken, then it investigated by using a Quanta 200 ESEM FEG from FEI Scanning Electron Microscope (SEM) $[6,7]$.

X-ray diffraction analysis: X-ray diffraction of fabrics used in order to identify the type of dirt, mordents in fibers, and any crystalline matters in the historical Carpet. The investigation was carried out with a SIEMENS X-Ray Diffractometer-D 5000, given $40 \mathrm{Kv} \mathrm{CU} \mathrm{Ka}$, radiation of $30 \mathrm{~mA}$. The diffractograms were recorded over $2_{-}=50$ to 300 continuously at a scan rate of $20 /$ min [8-10]. (Figure 2) 

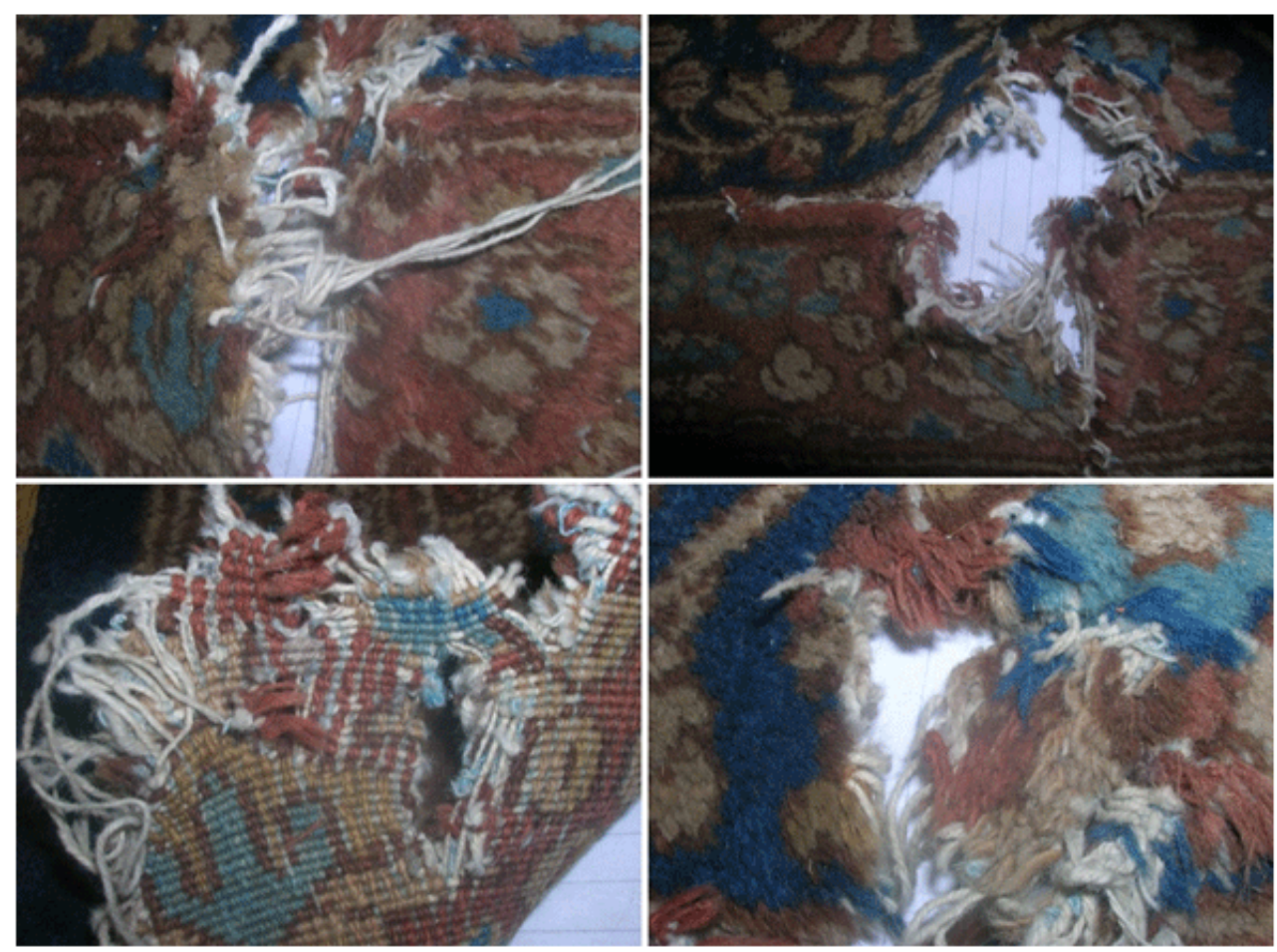

Figure 1: Show the Historical Carpet. One can see the deterioration aspects on the object such as missing parts, weak parts
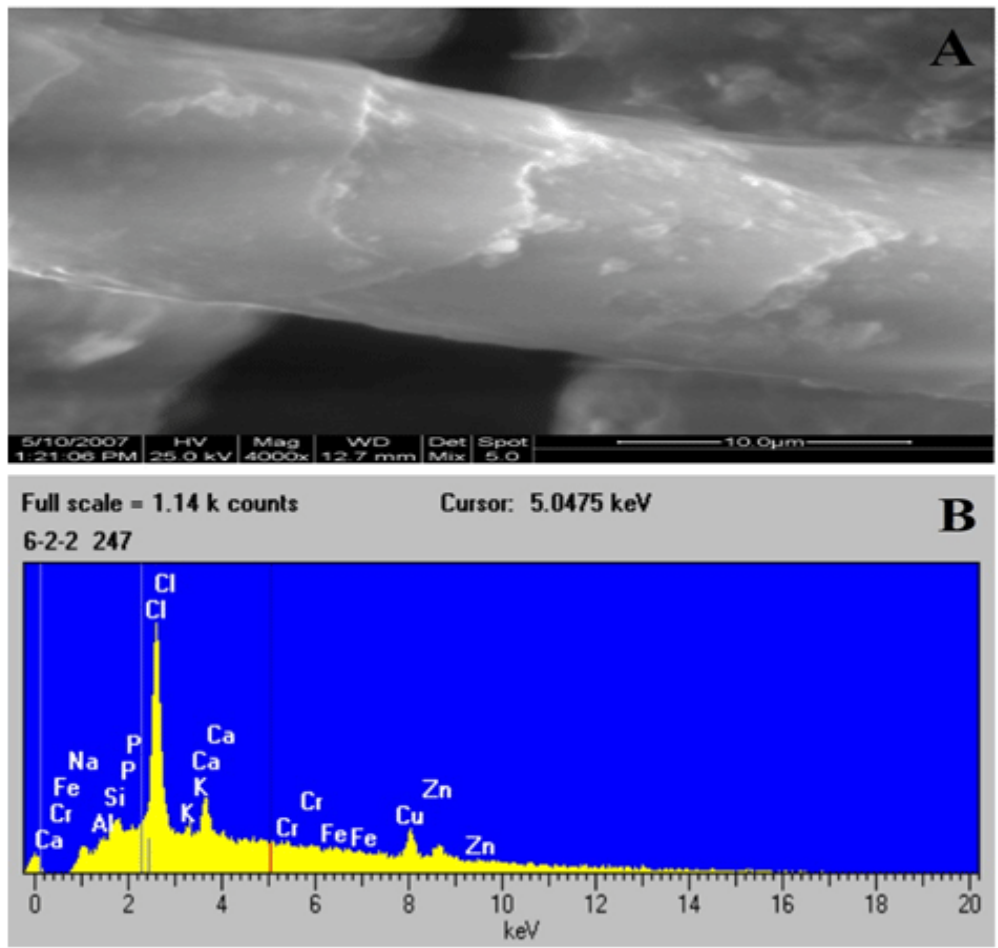

Figure 2: Show the SEM of Historical Carpet that show the fibers is wool (A). XR-D of Historical Carpet that show the type of dust and dirt (B)

Citation: Ahmed HE (2018) Conservation Strategies of a Rare Historical Carpet in Cairo University, A case study. Int J Fashion Technol Textile Eng 1(1): 1-6. 


\section{Testing the stability of dyes}

The stability of the color test: UTesting the stability of dyes in colored carpet and is a very important step before wet cleaning process. This is step was done by using washing solution in small sparse parts of the historical carpet parts. It was found that all the dyes were stable and did not bleed with the wet cleaning solution [11] [12].

Support of the week parts: The final step before cleaning process is to apply support to the weak part in the Historical
Carpet. This step is done by using stitching in order to protect the vulnerable part of the Carpet from disintegrating during the different cleaning processes [13]. (Figure 3)

Mechanical cleaning: Firstly, mechanical cleaning using different types of brushes, sizes and shapes. In addition, by using air suction using vacuum cleaner was done. This step is very important to get rid of dust and impurities not chemically attached to the surface of the carpet and to prepare the carpet for a wet cleaning process $[14,15]$. (Figure 4)
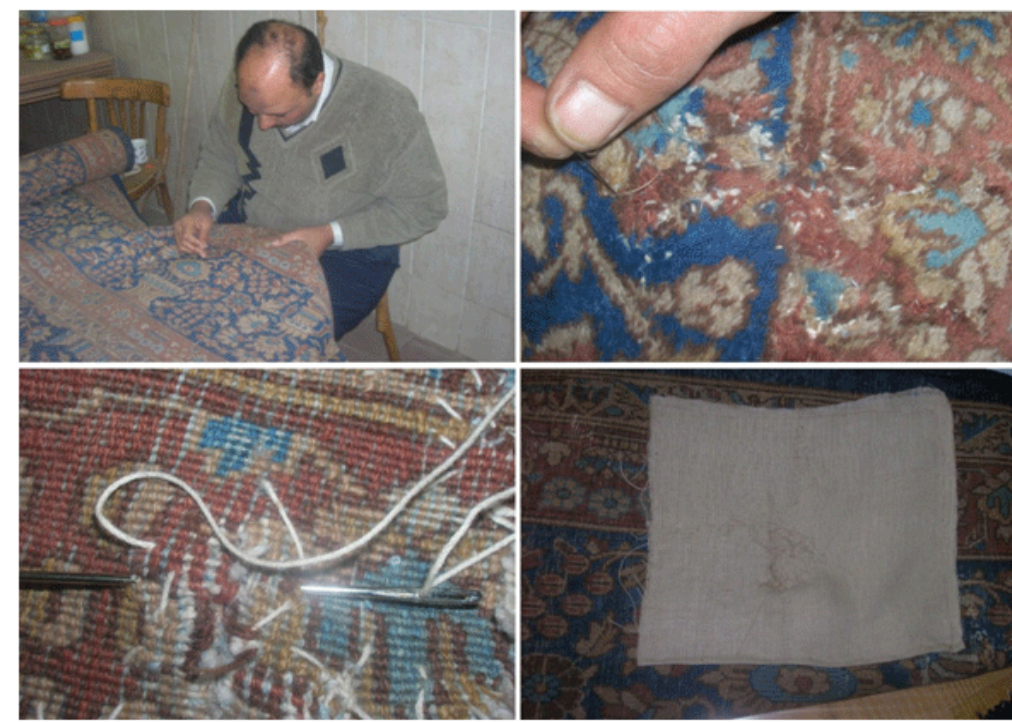

Figure 3: Show the support process of the weak parts and complete the missing parts of Historical Carpet before cleaning process
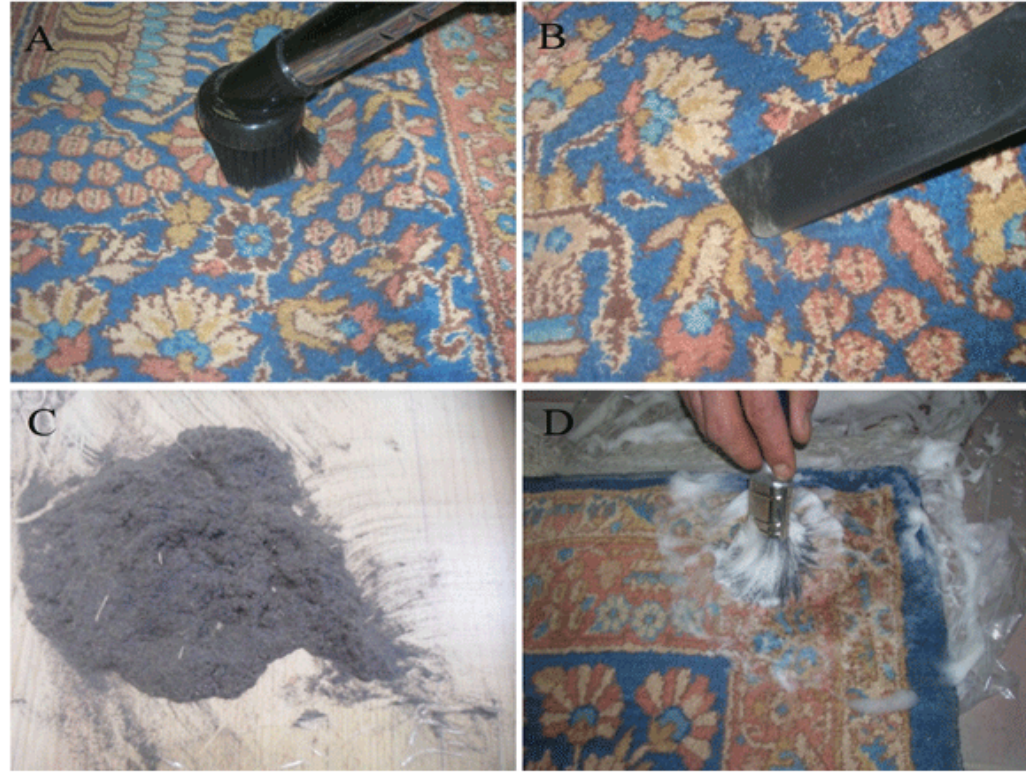

Figure 4: Show mechanical cleaning by vacuum (A and B). The dirt and dust that fund in the Historical Carpet (C). The stability of the color test (D)

Citation: Ahmed HE (2018) Conservation Strategies of a Rare Historical Carpet in Cairo University, A case study. Int J Fashion Technol

Textile Eng 1(1): 1-6. 
The wet cleaning procedure: A large temporary washing bath was set up using four wooden beams and then lined with polyethylene. The historic carpets were carefully placed in this temporary basin.

The ratio of cleaning solution was one part detergent Synperonic N to 100 parts of distilled water. With the use of a large size, brushes to help in the solution of washing solution between the carpet knots to get rid of the impurities and dust associated with the chemical surface carpet. Two wash baths were used with water only to get rid of the dissolved dirt and stain and to remove the residue of the cleaning solution. The wet cleaning reduced the soiling, relaxed the fibers, removed the creasing and brightened the colors [16-18] [19].
The drying process: It is very important in carpet restoration to quickly eliminate the wet condition after cleaning operations. Wet condition for long time may be cause innate growth or bleed the dyes. Therefore, after the wet cleaning process was completed, a free acid cotton cloth was used to absorb the remaining water in the carpet after wet cleaning process. After that, the heaters were then placed near the carpet to increase the temperature and warm up the environment around the wetted carpet to help drying process of the carpets.

After almost two days, the Historical Carpet was dried and it is ready for other conservation process [20, 21]. (Figure 5)
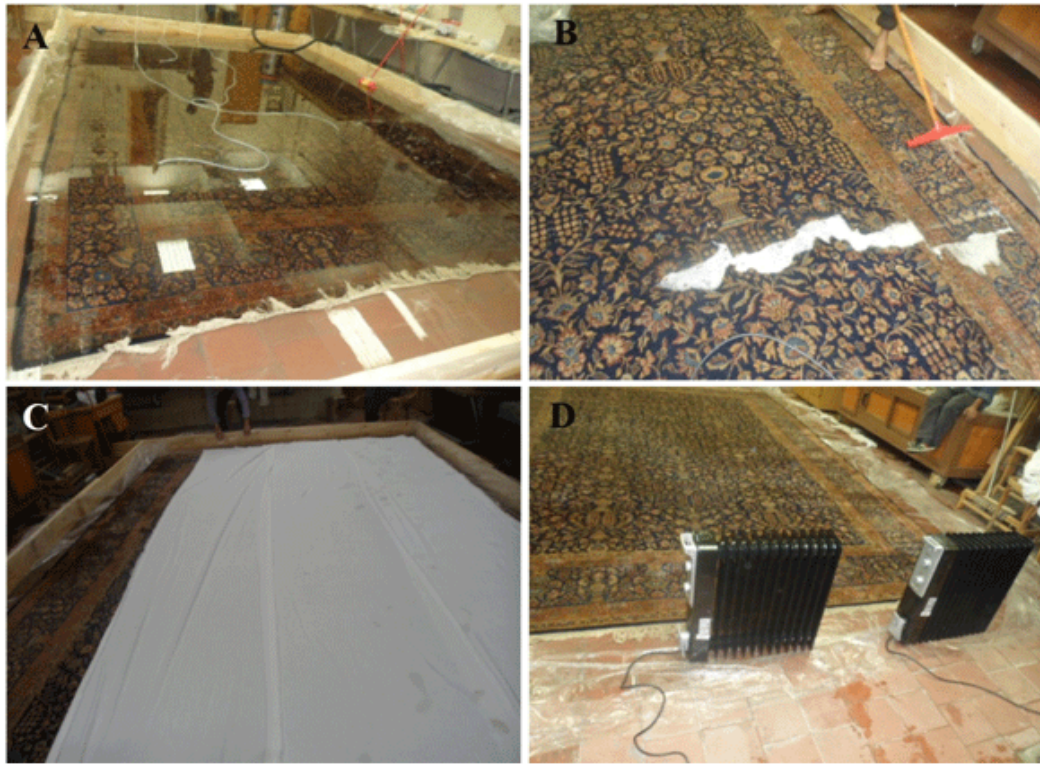

Figure 5: Show wet cleaning by using water and detergents of historical Carpet (A and B). The drying process of the object after wet cleaning (C and D)

Final support process: After the completion of the documentation process, initial support and different cleaning process of the Historical Carpet. The final supporting of the carpet by using new linen fabric and adhered it in the back of the carpet to protect it in the future is a very important step. Therefore, a new linen fabric was soaked in water with natural detergent for 12 hours and then boil for 1 hour to get rid of finishing materials of linen, then linen was treated against fungal damage. The new linen was adhered on the back of the carpet by using a narrow shingle to ensure future protection. Also installed on the edges of the carpet on the linen supported. The carpet is now ready for re-use after it has been cleaned and disposed of stains and also been strengthened and restored [22, 23]. (Figure 6) 

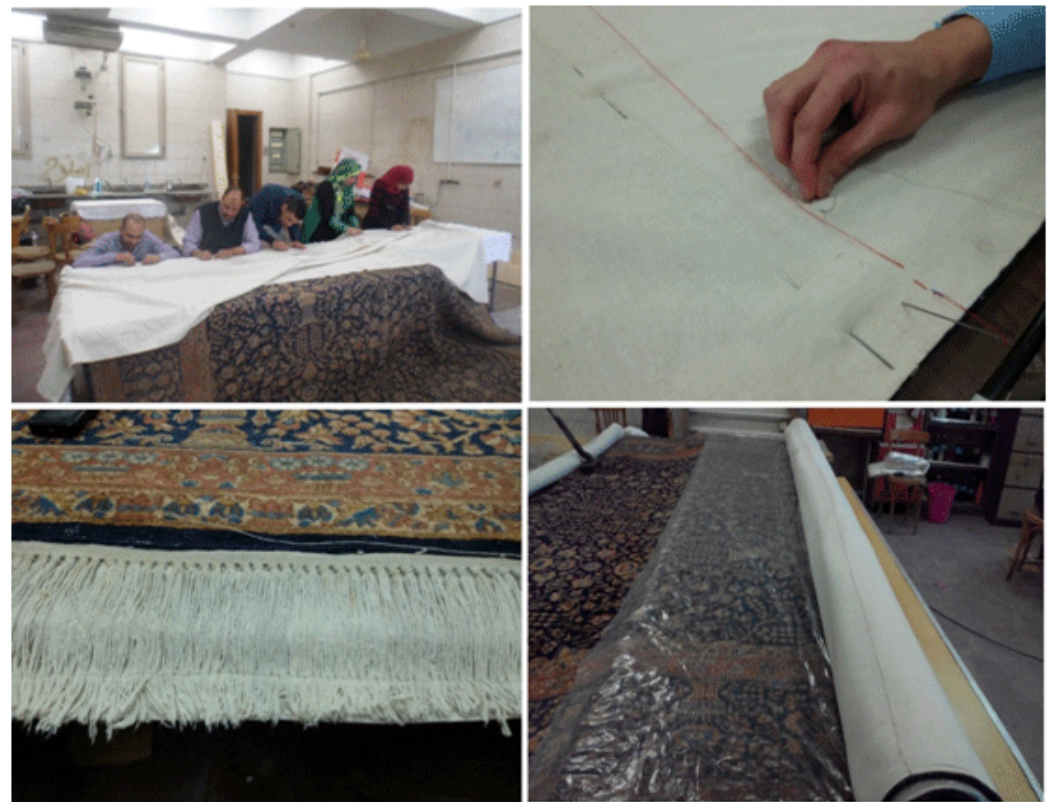

Figure 6: Show the final support of the historical Carpet by adhering new linen fabric to the background of the object by using stitching

\section{Conclusion}

Historical carpets are exposed to many factor of damages due to use such as dust, blur color grades, weakness, loss of some parts, and change of ph value. Therefore, the historical carpet requires to conservation process to eliminate the deterioration effects and protect the carpet for long term. Tests and analysis are used to identify carpet materials and damage aspect. Initial support and test of color stability is an important step before cleaning process. Mechanical cleaning process to remove the dirt and dust, as well as wet cleaning for disposal of impurities and dust, are important for carpet maintenance. The entire conservation step recorded by using photographs.

\section{References}

1. Mansour M, H Ahmed. Occurrence of fungi on some deteriorated ancient Egyptian materials and their controlling by ecofriendly products. Egyptian Journal of Archaeological and Restoration Studies, 2012;2(2):91-101.

2. Harby E Ahmed, Sameh M Reda, Dina Yehia, Yassin Ziddan. Preventive Conservation of Historic Textile from the Ultraviolet Degradation due to Light Exposure in Egyptian Museums. International Journal of Materials Science and Applications. 2016;5(6):10-14.

3. Ahmed HE. History of Natural Dyes in North Africa 'Egypt'. Handbook of Natural Colorants. 2009;27-36.

4. Landi S. The textile conservator's manual. 1998;Routledge.

5. Tímár-Balázsy Á, D Eastop. Chemical principles of textile conservation. 1998;Routledge.
6. Ahmed HE, FN Kolisis. A study on using of protease for removal of animal glue adhesive in textile conservation. Journal of Applied Polymer Science. 2012;124(5):3565-3576.

7. Batcheller JC. Optical and scanning electron microscopy techniques for the determination of hair fibres from Romano-Egyptian textiles. Scientific analysis of ancient and historic textiles: informing preservation, display and interpretation: postprints, first annual conference. 2004;51-56. Archetype Publications. 2005.

8. Harby Ezzeldeen Ahmed, Yuan Liu, Matthieu Baudelet, Bruno Bousquet, Martin Richardson. Investigation of historical Egyptian textile using laser-induced breakdown spectroscopy (LIBS)-a case study. Journal of Textile and Apparel, Technology and Management. 2013;8(2).

9. Nassef OA, HE Ahmed, $M$ Harith. Surface and stratigraphic elemental analysis of an ancient Egyptian cartonnage using LaserInduced Breakdown Spectroscopy (LIBS). Analytical Methods. 2016;8(39):7096-7106

10. Ahmed HE, OA Nassef. From Ptolemaic to modern inked linen via laser induced breakdown spectroscopy (LIBS). Analytical Methods. 2013;5(12):3114-3121

11. Ahmed H. Identification and Conservation of A Rare Islamic Textile Decorated with Metallic Yarns. Egyptian Journal of Archaeological and Restoration Studies. 2013;3(1):39-45.

12. Ahmed H, D Yahia, Y Zidan. Restoration and Storage Procedures of a Rare Historical Textile in the Museum of the Faculty of Applied Arts of Helwan University, Egypt. Egyptian Journal of Archaeological \& Restoration Studies. 2018;8(1):35-43. 
13. Abdel-Kareem 0. Conservation and restoration of a rare large Persian carpet. E-Conservation Magazine. 2010;17:53-63.

14. ahmed HE. Strategy for Preservation of Ptolemaic Wrapped Mummy's Linen in Tuna El-Gebel Excavation, Egypt. A Case Study. International Journal of Conservation Science. 2011;2(3):155-164.

15. Fiette A. Tapestry restoration: an historical and technical survey. The Conservator. 1997;21(1):28-36.

16. Ahmed HE. First Aid of Rare Ptolemaic Textile in Tuna El-Gebel Excavation, Egypt. Age. 2:3.

17. Mason TJ. Ultrasonic cleaning: An historical perspective. Ultrasonics sonochemistry. 2016;29:519-523.

18. Aslanidou D, C Tsioptsias, C Panayiotou. A novel approach for textile cleaning based on supercritical $\mathrm{CO} 2$ and Pickering emulsions. The Journal of Supercritical Fluids. 2013;76:83-93.
19. Ahmed HE, SS Gremos, FN Kolisis. Enzymatic Removal of the Oily Dirt from a Coptic Tunic using the Enzyme Lipase. Journal of Textile and Apparel, Technology and Management. 2010;6(3).

20. Osman EM, YE Zidan, NK Fahim. The Determination of Conservation State of Archaeological Moroccan Kilim by Physical Analytical Methods. International Journal of Conservation Science. 2017;8(1).

21. Quye A, F Lennard. Materialising Conservation Science Research for Historical Textiles. 2015.

22. Karimnejad MM, MA Boyaghchi, B Zolfaghari. Evaluation and Optimization of Acanthophyllum Extract in Washing of the Historical Textiles. IJAPAS. 2017;2(4):7-14.

23. Pow CV. The conservation of tapestries for museum display. Studies in conservation. 1970;15(2):134-153. 